\title{
Positive correlation between pre- and postconditioning saccharin intake in taste-aversion learning
}

\author{
TREVOR ARCHER and PER-OLOW SJÖDÉN \\ University of Uppsala, S-751 04 Uppsala, Sweden
}

\begin{abstract}
Data from 36 groups of rats from a total of 12 taste-aversion (saccharin+lithium chloride) experiments were analyzed for (1) individual differences of absolute saccharin (sacc) intake on the first (conditioning) and second (test) presentations, and (2) the correlation between intakes on the two presentations. Large individual differences and strong positive correlations were found for sacc $+\mathrm{LiCl}$, sacc $+\mathrm{NaCl}$, sacc- $\mathrm{LiCl}$ unpaired, and "different context" conditions. In addition to raising doubts about the use of absolute saccharin intake as a measure of taste-aversion learning, these results support the view that an associative (taste-nausea) component is superimposed on a neophobic avoidance of the novel taste stimulus.
\end{abstract}

On the first presentation of a novel taste solution, rats typically show a neophobic response; i.e., they consume less of the novel solution as compared to a familiar one (Carroll, Dinc, Levy, \& Smith, 1975; Mitchell, Kirschbaum, \& Perry, 1975; Rozin, 1969; Wittlin \& Brookshire, 1968). This phenomenon has an obvious survival value for an omnivorous species, since individuals with a strong neophobic response may survive, even if the taste substance is poisonous. However, omnivorous species would also be expected to contain a number of individuals with weak neophobic reactions, since a novel substance may be advantageous or become advantageous for survival if the ecological circumstances change. Garcia, Ervin, and Koelling (1967) have reported individual differences of taste-aversion learning to be practically nonexistent. On the other hand, Elkins (1973) demonstrated marked individual differences of absolute saccharin intake as well as of saccharin preference values after a single conditioning trial. Both of these studies were concerned only with individual differences of taste-aversion learning. No attempts were made to investigate the possible contribution of individual differences in taste neophobia to the results obtained. Thus, it is possible that such differences present already during the saccharin exposure on the conditioning trial may have contributed to the individual variation in, e.g., Elkins' (1973) data.

A number of studies have investigated the relationship between the amount of the taste substance consumed on the conditioning trial and on a subse-

Valuable comments were provided by Ned Carter and Les Shaps. The present research was supported by Grant 1128/77 from the Swedish Council for Research in the Humanities and Social Sciences and by grants from the University of Uppsala. Request reprints from Trevor Archer, Department of Psychology, Uppsala University, Box 227, S-751 04 Uppsala, Sweden. quent test trial. Bond and his co-workers (Bond \& DiGiusto, 1975; Bond \& Harland, 1975) have reported a negative correlation in that the greater the amount drunk on the conditioning trial, the smaller the amount consumed in a later test, i.e., the greater the aversion. Barker (1976) found the same relationship up to $3 \mathrm{ml}$ of initial saccharin intake, above which the degree of aversion was asymptotic. Braveman and Crane (1977) reported a negative correlation between the amounts drunk on the first and second exposures up to $5.5 \mathrm{ml}$ of initial intake and a positive correlation above that value. Finally, Kalat (1976) and Smith and Morris (1963) found no relationship between amount of initial intake and the resulting aversion.

Provided that omnivorous species contain individuals with varying degrees of taste neophobia, it seems reasonable to expect large individual differences in an unselected group of rats in the amount of saccharin drunk on the first presentation. For this to be detected, however, the animals must be allowed a sufficiently long period of drinking for individual differences to express themselves. In those studies where the relationship between the amount of solution drunk on conditioning and taste-aversion learning has been investigated, the amount of solution drunk (Bond \& DiGiusto, 1975; Bond \& Harland, 1975; Braveman $\&$ Crane, 1977), the number of licks (Barker, 1976), or the duration of the initial drinking period (Kalat, 1976) has been determined by the experimenter. Furthermore, when duration has been controlled, very short periods of drinking have been used (Kalat, 1976). Thus, in none of these studies have individual differences in intake of the solution on the first exposure been considered.

The present study was aimed at investigating what, if any, relationship would hold between amount of 
saccharin drunk on conditioning and subsequent taste aversion when rats were allowed to taste the solution for a sufficiently long period in order that individual differences might express themselves. Thus, the amount of saccharin consumed on the conditioning trial was correlated with absolute saccharin intake on a subsequent presentation, utilizing data from a great number of experiments performed recently at our laboratory.

\section{METHOD}

The data reported here consist of observations of saccharin intake by a total of 222 rats on two successive saccharin presentations in 12 separate experiments. Although the experiments were originally designed to test several different hypotheses, they share all methodological elements crucial for a consideration of the problems raised in the present paper.

\section{Subjects}

All 222 subjects in the present study were male Sprague-Dawley rats (AB Anticimex, Sollentuna, Sweden), weighing approximately $225 \mathrm{~g}$ (range $200-250 \mathrm{~g}$ ) at the beginning of the experiments. Within each experiment, all groups $(n=6$ or 8$)$ were matched for body weight.

\footnotetext{
Apparatus

The exteroceptive background context in which the saccharin presentations were made consisted of three components that varied between conditions (see Table 1): (a) housing-." "contextual" compartments $(15 \times 35 \times 20 \mathrm{~cm})$, opaque plastic boxes with light excluded by Masonite covers except for two small holes for the drinking bottles, or "normal" individual Perspex cages (16.5 $\times 22.5 \times 13.5 \mathrm{~cm}$ ) with gridded metal covers with spaces for food and water bottle; (b) drinking bottles-either "noisy" bottles (Techniplast, Italy), with metal nozzles having a 6-mm hole at the tip and containing a small metal ball which created a significant amount of noise when the animals licked the tops of the nozzles, or "silent" bottles, which were standard glass bottles with metal nozzles having a 2-mm opening at the tip; and (c) odor-either a distinctive mentholated odor (Vicks Vapo Rub, RichardsonMerrell, London) impregnated on the inside of the "contextual" compartments or on wooden boards outside the cages, or no particular odor.
}

\section{Procedure}

All animals received a 2-week acclimatization on a 12-h-on/ 12-h-off lighting schedule in a room thermostatically maintained between $21^{\circ}$ and $23^{\circ} \mathrm{C}$. Ad-lib food (lab chow R3, Astra-Ewos, Södertälje, Sweden) and water in "silent" bottles were available to all animals except those in Condition $C$ (Table 1), for which water was present in "noisy" bottles. All animals received between 4 and 6 days of training to a $30 \mathrm{~min} /$ day drinking schedule beginning with a 60 -min exposure, subsequently reduced to $30 \mathrm{~min}$. This training took place under the identical laboratory conditions as for acclimatization, except for the rats in Condition B (Table 1), which were placed in "contextual" compartments in the presence of the odor and received water in "noisy" bottles.

Conditions A-E. These conditions consisted of experimental groups from the original experiments; i.e., $\mathrm{LiCl}$ was given contingently on the first saccharin presentation, and the exteroceptive contexts of the first two saccharin exposures were identical.

On the first saccharin exposure, the animals in Condition $B$ were placed in "normal" cages, while those in Conditions A, D, and $\mathrm{E}$ were placed in "contextual" compartments. The animals in Conditions A, C, and E were exposed to the odor, while those in Condition $\mathrm{D}$ were placed in an odor-free room. Following these manipulations, the animals in Conditions $A, C, D$, and $E$ were offered saccharin $(.2 \%$ solution) in "noisy" bottles for $30 \mathrm{~min}$, while those in Condition B received saccharin in "silent" bottles. Thus, the animals in Conditions A, C, D, and E were allowed to drink saccharin in the presence of either compartments + "noisy" bottles and/or odor stimuli, while those in Condition B, in "normal" cages, drank saccharin from the "silent" bottles in the absence of the odor. Approximately $15 \mathrm{~min}$ after the termination of the drinking period, each rat was given an intraperitoneal (IP) injection of $2.5 \mathrm{ml}, .15 \mathrm{M} \mathrm{LiCl}$ and immediately replaced in its particular environment.

Twenty-four hours after the first saccharin presentation, the animals in Conditions A, B, C, and D were offered saccharin for $30 \mathrm{~min}$ after having been handled in their respective environments. The second saccharin presentation for the $\mathrm{E}$ condition took place $48 \mathrm{~h}$ after the first, and a 30 -min period of water drinking was interposed on the day in between.

Conditions F-H. Animals in Conditions F-H served as control groups in the original experiments, and they showed an increase of saccharin intake from the first to the second presentation. In the present report, 13 such groups were included, and they received three different types of treatment: (a) "different context" groups (Condition F), placed in "contextual" compartments with "noisy" bottles and odor on the first saccharin exposure, which was followed by a $\mathrm{LiCl}$ injection. Twenty-three hours later, they were moved to "normal" cages with "silent" bottles and no odor

Table 1

Mean Saccharin Intake, Correlations, and Mean Taste Suppression Ratios on Two Presentations for Conditions A-H

\begin{tabular}{|c|c|c|c|c|c|c|c|c|c|}
\hline \multirow{3}{*}{$\begin{array}{c}\text { Condi- } \\
\text { tion }\end{array}$} & \multirow{3}{*}{$\begin{array}{c}\text { Number of } \\
\text { Groups }\end{array}$} & \multirow[b]{3}{*}{$N$} & \multicolumn{4}{|c|}{ Saccharin Intake (in grams) } & \multirow{3}{*}{$\begin{array}{l}\text { Correlation 1st- } \\
\text { 2nd Presentation }\end{array}$} & \multirow{2}{*}{\multicolumn{2}{|c|}{ Taste Suppression Ratio }} \\
\hline & & & \multicolumn{2}{|c|}{ 1st Presentation } & \multicolumn{2}{|c|}{ 2nd Presentation } & & & \\
\hline & & & Mean & SD & Mean & $\mathrm{SD}$ & & Mean & SD \\
\hline A & 7 & 42 & 11.5 & 3.5 & 5.5 & 2.7 & $+.578 *$ & .47 & .20 \\
\hline B & 2 & 12 & 10.3 & 2.3 & 4.3 & 2.4 & +.539 & .46 & .17 \\
\hline $\mathrm{C}$ & 2 & 16 & 17.5 & 3.2 & 9.4 & 2.9 & $+.744^{*}$ & .53 & .11 \\
\hline D & 3 & 18 & 10.4 & 3.3 & 4.8 & 2.0 & $+.637^{*}$ & .46 & .18 \\
\hline $\mathbf{E}$ & 9 & 54 & 13.1 & 3.0 & 5.3 & 2.5 & $+.704 *$ & .39 & .16 \\
\hline $\mathrm{F}$ & 7 & 42 & 9.3 & 5.4 & 12.9 & 4.9 & $+.710^{*}$ & 1.47 & .91 \\
\hline G & 3 & 18 & 11.6 & 3.6 & 15.7 & 2.2 & +.380 & 1.43 & .72 \\
\hline $\mathrm{H}$ & 3 & 20 & 12.4 & 4.9 & 18.3 & 2.1 & +.400 & 1.66 & .59 \\
\hline
\end{tabular}

Note-Mean taste suppression ratios were based on the ratios between amounts drunk on the second and first presentations for individual animals. $\quad{ }^{*} p<.01$. 
for the second saccharin presentation. The rationale for including these groups in the control condition, in spite of their having received a saccharin $+\mathrm{LiCl}$ exposure, is that the change of exteroceptive context reliably results in virtually no demonstrable aversion to the taste substance employed (Archer, Sjodén, Nilsson, \& Carter, 1979); (b) placebo groups (Condition G), receiving a $2.5 \mathrm{ml}, .11 \mathrm{M} \mathrm{NaCl}$ injection (IP) after the first saccharin presentation: and (c) unpaired groups (Condition $\mathrm{H}$ ), to which the $\mathrm{LiCl}$ injection was given after water drinking in "normal" cages with "silent" bottles $24 \mathrm{~h}$ prior to the first saccharin presentation. For Conditions $\mathrm{G}$ and $\mathrm{H}$, both saccharin presentations were performed in "contextual" compartments with "noisy" bottles and odor present.

\section{RESULTS}

Table 1 (Column 8) shows product-moment correlations between mean intakes on the first and second saccharin presentations for Conditions A-H. All correlations were positive and, with the exception of Conditions B, G, and $\mathrm{H}$, statistically significant (t tests, $p<.01$; Hays, 1963, p. 661). Figure 1 presents a plot of the data from all rats in Conditions A-E and the correlation based on intake data from all 142 rats in these conditions. It is obvious that the intake data from both saccharin presentations show a roughly normal distribution, that there are marked individual differences of the amounts consumed on the first and second presentations, and that there is a strong positive correlation. A plot of the data from the animals in Conditions F-H shows a very similar pattern. The overall correlation based on data from all 80 rats of Conditions F-H was +.576 $(\mathrm{p}<.01)$. Thus, it can be concluded that the amount of saccharin spontaneously consumed by rats on the initial presentation is positively correlated with the amount consumed on the second presentation. This relationship holds for groups showing an aversion as well as for those that do not and is true in spite of the variation in the exteroceptive contexts between the various conditions.

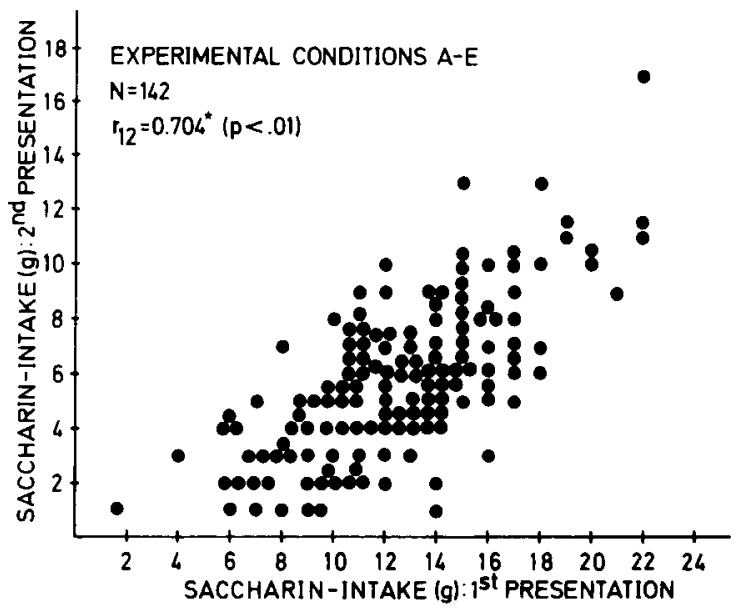

Figure 1. Saccharin intake of 142 rats on two successive presentations.
It may be argued that the individual differences of saccharin intake simply reflect individual differences of fluid intake in general, rather than neophobia differences. Thus, we correlated the amount of water drunk on the last day of water drinking with saccharin intake on the first exposure for the animals in Conditions $\mathrm{C}, \mathrm{D}$, and $\mathrm{H}$, for which water data were available. Correlations were $+.053,+.259$, and +.313 , respectively. These values were not statistically significant. In addition, water data were available for a total of 68 rats from experiments not otherwise included in the present report. The watersaccharin correlation for these rats was +.002 . These findings support the notion that individual differences of saccharin intake on the first exposure are not simply a reflection of individual differences of fluid intake.

The individual differences of saccharin intake on the second saccharin presentation could be predicted largely from the individual differences in taste neophobia on the first presentation. The absolute intake of saccharin on the second presentation is routinely used as a measure of taste-aversion learning. The correlations presented above raise serious doubts as to the appropriateness of this as a measure of learning. As an alternative, we computed taste suppression ratios (TSR) (cf. Lyon, 1968) as the quotient of the amounts of saccharin consumed by individual rats on the second and first presentations, thus correcting for individual neophobia differences. Mean TSRs are shown in Table 1, Column 9. It is evident that the intake of saccharin decreased to a similar degree from the first to the second presentation in all contingently poisoned conditions except E. An analysis of variance of a completely randomized design with unequal groups yielded a significant $F$ value $[F(4,137)=3.3, p<.05]$. Subsequent $t$ tests (Kirk, 1968, p. 74) indicated a significant $C>E$ difference only $(t=2.4$, df $=137, p<.02)$. This is likely to be due to the fact that the $E$ rats had the opportunity to drink water on the day between saccharin presentations, and may therefore have been less fluid deprived than the $\mathrm{C}$ rats at the second presentation. Saccharin intake increased to a similar degree in the nonpoisoned, noncontingently poisoned, and "different context"' groups. Analysis of variance indicated no significant differences among TSR values for these groups.

\section{DISCUSSION}

The present data warrant three major conclusions: (1) There are great individual differences among rats in the intake of saccharin on the first presentation; (2) to a large extent, these differences predict the individual differences of amount of saccharin drunk on the presentation after the conditioning trial; (3) the 
strong positive correlations of absolute intake between the first and second exposures raise serious doubts as to the appropriateness of absolute intake as a suitable measure of taste-aversion learning. A taste suppression ratio (TSR) is proposed as an alternative.

The first two conclusions confirm our expectation that there should be individual differences in the neophobic reaction of rats to a novel taste. The lack of correlation between previous water intake and saccharin intake on the first presentation suggests that these are, indeed, neophobia differences. Furthermore, these conclusions raise the possibility that the individual differences of taste-aversion learning found by Elkins (1973), employing absolute intake and relative preference for saccharin as measures of learning, were reflections of individual differences of taste neophobia.

The third conclusion touches upon the general question of how to devise an appropriate measure of taste-aversion learning. The conditioning procedure can be conceptualized as aimed at changing the "value" of the taste stimulus. The dependent variables are therefore, by necessity, indirect measures. However, the variables chosen should not be influenced by the initial reactions of the animals to the taste stimulus, since they are intended as measures of learning. The present results indicate that absolute intake of a substance may not be an appropriate measure when individual differences of taste neophobia are allowed to express themselves. Two general strategies seem to be possible here. (1) Present predetermined amounts of the taste substance on the conditioning trial (cf. Barker, 1976; Bond \& DiGiusto, 1975; Bond \& Harland, 1975; Braveman \& Crane, 1977). This strategy eliminates individual differences in the amount consumed. However, it entails the disadvantage that individual differences of drinking duration may be present, and these are not easily assessed. Furthermore, this strategy may make the laboratory study of tasteaversion learning less representative of the baitshyness phenomenon as it occurs under natural conditions, where individual neophobia differences obviously are allowed. (2) Control the duration of the drinking period (Kalat, 1976). With this strategy, individual differences will occur, provided that long enough periods of drinking are employed. In this case, the use of a taste-suppression ratio seems indicated. In general, in taste-aversion experiments, a safe strategy seems to be to assess initial water intake and intake of the taste substance on the first two presentations, to assess individual differences, and to compute relevant correlations. In the case of significant correllations, we propose the use of the TSR, which more directly than absolute intake or relative preference measures reflects the change of "value" of the taste stimulus caused by the conditioning trial. Further research is needed to validate the TSR, for example, by investigating how it relates to the number of conditioning trials and CS intensity.

The finding that the amount of saccharin drunk on conditioning shows a strong positive correlation with the amount of saccharin intake on testing is opposite to the results of Bond and DiGiusto (1975) and Bond and Harland (1975), who obtained a negative correlation, and Barker (1976) and Braveman and Crane (1977), who found a negative correlation up to 3 and $5.5 \mathrm{ml}$ of initial intake, respectively. However, in the Bond studies, the volume of saccharin presented was varied by the experimenter between 0 and $5.5 \mathrm{ml}$ by making the rats drink a specific amount at their own rate. Barker (1976) allowed the animals a predetermined number of licks at a saccharincontaining tube and Braveman and Crane (1977) employed the Bond procedure. Thus, in these studies, individual differences of the neophobic response to saccharin were overruled. Other workers (Kalat, 1976; Smith \& Morris, 1963) have found no particular relation between saccharin intake on the conditioning trial and later taste-aversion testing. Kalat (1976) presented various taste substances for limited durations. Of the 29 different groups employed, 19 were allowed to drink for $2.5 \mathrm{~min}, 9$ for $5 \mathrm{~min}$, and 1 for 10 min (Kalat, 1976; Table 1, Column 2). Consequently, the volume consumed on conditioning was rather low, never exceeding a mean value of $7.2 \mathrm{ml}$. In the study by Smith and Morris (1963), saccharin was presented for 20 min to rats with varying thirst levels, and the volume consumed varied from 4.6 to $9.2 \mathrm{~g}$ on the first exposure. Thus, the previous studies differ from the present study also with respect to the amount of saccharin drunk on the conditioning trial. The single previous study reporting a positive correlation between pre- and postconditioning saccharin intake is that by Braveman and Crane (1977). However, these authors found a positive correlation only when the initial intake exceeded $5.5 \mathrm{ml}$. In the present report, only two rats drank less than $6 \mathrm{ml}$ on the first exposure (Figure 1). Thus, the present data support the conclusion by these authors (Braveman \& Crane, 1977) that increasing the amount of solution drunk (or the duration of drinking) above a certain value leads to increasingly weaker aversions as assessed by absolute intake.

A growing number of reports, indicating the importance of taste neophobia in taste-aversion learning, suggest that both associative and nonassociative processes operate in this situation (see Mitchell, Scott, \& Mitchell, 1977, for review). The present results, showing an approximate reduction of saccharin intake of about $50 \%$ in the contingently poisoned groups on the second presentation, irrespective of the amount of saccharin drunk on the initial exposure, strongly supports the suggestion that 
the associative CS-UCS component is superimposed on a neophobic reaction to the novel taste + exteroceptive context in taste-aversion conditioning (Mitchell, Hoch, \& Fitzsimmons, 1975; Mitchell, Parker, \& Johnson, 1976).

\section{REFERENCES}

ArCher, T., SuöD́en, P. O., Nilsson, L.-G., \& Carter, N. Role of exteroceptive background context in taste-aversion conditioning and extinction. Animal Learning \& Behavior, 1979, 7, 17-22.

BARKER, L. M. CS duration, amount, and concentration effects in conditioning taste aversions. Learning and Motivation, 1976. 7, 265-273.

Bond, N., \& DiGiusto, E. Amount of solution drunk is a factor in the establishment of taste aversion. Animal Learning \& Behavior, 1975, 3, 81-84.

Bond, N., \& HaRland, W. Effect of amount of solution drunk on taste-aversion learning. Bulletin of the Psychonomic Society, 1975, 5, 219-220.

Braveman, N. S., \& Crane, J. Amount consumed and the formation of conditioned taste aversions. Behavioral Biology, 1977, 21, 470-477.

Carroll, M. E., Dinc, H. I., Levy, C. J., \& SMith, J. C. Demonstration of neophobia and enhanced neophobia in the albino rat. Journal of Comparative and Physiological Psychology, $1975,89,457.467$.

ElkINs, R. L. Individual differences in bait shyness: Effects of drug dose and measurement technique. Psychological Record, 1973, 23, 349-358.

Garcia, J., Ervin, F., \& Korlling, R. Bait shyness: A test for toxicity with $\mathrm{N}=2$. Psychonomic Science, 1967, 7, 245-246.
HAYs, W. L. Statistics for psychologists. New York: Holt, Rinehart \& Winston, 1963.

Kalat, J. W. Should taste-aversion learning experiments control duration or volume of drinking on the training day? Animal Learning \& Behavior, 1976, 4, 96-98.

KIRK, R. E. Experimental design: Procedures for the behavioral sciences. Belmont, Calif: Brooks/Cole, 1968.

LyoN, D. O. Conditioned suppression: Operant variables and aversive control. Psychological Record, 1968, 18, 317-338.

Mitcheli, D., Hoch, N. E., \& Fitzsimmons, M. Effects of neophobia sensitization on the rat's preference for earned food. Behavioral Biology, 1975, 13, 519.525.

Mitcheli, D., Kirschbaum, E. H., \& Perry, R. L. Effects of neophobia and habituation on the poison-induced avoidance of exteroceptive stimuli in the rat. Journal of Experimental Psychology: Animal Behavior Processes, 1975, 1, 47-55.

Mitchell, D., Parker, L. F., \& Johnson, R. Absence of a generalization decrement in the poison-induced avoidance of interoceptive stimuli in the rat. Physiological Psychology, 1976. 4, 121-123.

Mitchell, D., Scott, D. W., \& Mitchell, L. K. Attenuated and enhanced neophobia in the taste-aversion "delay of reinforcement" effect. Animal Learning \& Behavior, 1977, 5, 99-102.

RozIN, P. Central or peripheral mediation of learning with long CS-US intervals in the feeding system. Journal of Comparative and Physiological Psychology, 1969, 67, 421-429.

SMITH, J. C., \& MorRIs, D. D. Effects of atropine sulfate on the conditioned aversion to saccharin fluid with X-rays as the unconditioned stimulus. Radiation Research, 1963, 18, 186-190.

Wittlin, W. A., \& Brookshire, K. H. Apomorphine-induced conditioned aversion to a novel food. Psychonomic Science, 1968 , 12, 217-218.

(Received for publication March 15, 1978; revision accepted August 16, 1978.) 